\title{
Insuficiencias del reconocimiento para una apertura cosmopolita al otro
}

\author{
Antonio Aguilera Pedrosa \\ Universitat de Barcelona \\ antaguilera@ub.edu
}

Recibido: 12-06-2014

Aceptado: 21-04-2015

\section{Resumen}

Axel Honneth ha introducido la necesidad de comprender varios tipos de reconocimiento en las relaciones sociales (afectivo, social, económico) para revisar una teoría social basada en la comunicación como la de Habermas. En este texto, se intenta mostrar las limitaciones de tal concepto hegeliano para la teoría social, para la filosofía y para una política que permitiera realizar una apertura cosmopolita al otro. Desde una teoría de la subjetividad de raíz freudiana y lacaniana, se razona sobre las debilidades de la noción de reconocimiento incluso en las diversas reformulaciones de Honneth. Con el apoyo en algunas ideas de Wellmer, Menke, Benhabib, junto a la tradición de la teoría crítica modulada desde Derrida, se completa una crítica del uso teórico social y político de esa noción, proponiendo una «inclusión del otro» como más interesante teóricamente y que tendría que abarcar a la traducción para mostrar una perspectiva adecuada en la apertura cosmopolita al otro.

Palabras clave: Axel Honneth; reconocimiento; teoría crítica; cosmopolitismo; traducción.

\section{Abstract. The Limits of Recognition for a Cosmopolitan Openness to the Other}

Axel Honneth introduced the need to understand several types of recognition in social relations (affective, social, economic) to revise a social theory based on communication like that of Habermas. This text seeks to show the limitations of such a Hegelian concept for social theory, for philosophy and for a politics that might allow cosmopolitan openness to the other. From a theory of subjectivity rooted in Freud and Lacan, the weaknesses of a notion of recognition are reflected upon, even in Honneth's several reformulations. With recourse to some ideas by Wellmer, Menke and Benhabib, together with the tradition of critical theory as modulated through Derrida, a critique of the social-theoretical and political use of such a notion is formulated, proposing an 'inclusion of the other' as theoretically more interesting, which should also comprise translation in order to provide a suitable perspective for a cosmopolitan openness to the other.

Keywords: Axel Honneth; recognition; cosmopolitanism; critical theory; translation. 


\section{Sumario}

1. De vuelta a Hegel otra vez, pero cada vez de modo diferente

2. Reconocimiento como olvido de cierta cosificación

3. Más allá del reconocimiento: el desconocimiento del otro como condición clave
4. Inclusión del otro, no un mero reconocimiento

5. Allende el reconocimiento:

traducción como apertura

cosmopolita al otro

Referencias bibliográficas

Hay una tradición filosófica que todavía echa su sombra sobre la teoría social y la filosofía, sobre la ética y la política. Adorno hizo un movimiento filosófico peculiar que no todos los frankfortianos han seguido: poner nuestra época ante la mirada de Hegel y luego despedirse del idealismo. Creo que hoy ya no podemos quedarnos en aquella mirada de los hegelianos de izquierda, incluso modulada por un freudismo de izquierda, poniendo nuestra experiencia ante los ojos de un pensador clásico que todavía no pagaba el precio de una división del trabajo tardomoderna. El mismo Adorno trató de superar a Hegel en la idea de una dialéctica negativa que hay que entender como materialista. En sintonía con ello, o intentando ir más allá, es necesario reformular las cosas de otra manera, ya posthegeliana. El reconocimiento es una cuestión decisiva en Hegel y es un tema que ha suscitado muchas veces cuestiones de relevancia teórico-social, pero podría ser un paso atrás respecto a una teoría de la comunicación como base de la teoría social que todavía mantiene la tensión entre subsistemas sociales y mundo de la vida, que lo generaliza a una situación cosmopolita y da cabida a pensar complejas tensiones sociales y políticas. Pero se puede aprender de los pasos hacia atrás, ya que ayudan a seguir hacia delante con mayor seguridad.

Honneth ha intentando fundamentar la teoría social en el reconocimiento, al suponer que las luchas sociales estarían en el centro de la dinámica social y creyendo que, desde ahí, podría superar y abolir la tensión habermasiana entre racionalización sistémica y social. En otro extremo teórico - y de estilo también-, el primer Lacan pretendió apoyarse en el reconocimiento como clave para pensar la relación intersubjetiva en vistas a fundamentar una práctica psicoanalítica. En un contexto francés donde la crítica a Hegel se convirtió en clave para Derrida y otros, la aceptación del fracaso de esa tentativa por Lacan, lo que da en realidad la clave para entender la peculiar aportación al conocimiento de lo psicosocial, marca el desarrollo del lacanismo. No hay en Honneth una valoración equivalente que le lleve a un despido del reconocimiento abrazado al principio, pero sí un desplazamiento que quiero seguir para hacer presente algunas limitaciones del reconocimiento para la teoría social, para la filosofía y para una teoría del sujeto.

Al final de su Critica del poder, Honneth da una pista relevante para seguir su evolución intelectual. Tras haber repasado la historia de la teoría 
crítica y haber destacado la aportación de Foucault y de Habermas, manifiesta la necesidad de establecer una visión alternativa a la teoría comunicativa de la sociedad, destacando lo que Habermas abandona: «la posibilidad de una crítica justificada de las formas concretas de organización de la producción económica y la administración» (2009: 444). Honneth dice querer solucionar lo que la historia de la teoría crítica no ha conseguido formular bien «el potencial para un entendimiento del orden social como una relación comunicativa institucionalmente mediada entre grupos integrados culturalmente que, en la medida que el ejercicio del poder se distribuye de forma simétrica, tiene lugar en el medio de la lucha social» (2009: 444). Emerge una distancia respecto a Habermas, especialmente respecto a la división entre mundo de la vida y sistemas sociales, pero no sin paralelismos curiosos. Honneth apunta a una relación de entendimiento que está mediada institucionalmente y que se despliega en forma de luchas sociales, dentro de ciertos grupos sociales. Desde ahí, poco a poco, Honneth ha tratado de desplegar una teoría de la sociedad que pone en el centro las relaciones de reconocimiento, como antes Habermas lo había hecho con el entendimiento, con la racionalidad comunicativa. Pero no parece pretender tanto como Habermas, cuando éste afirma un cambio del paradigma filosófico que lleva de la vieja primacía de la consciencia o del sujeto a la relevancia de la intersubjetividad comunicativa, en ese doble giro lingüístico que introduce uno pragmático al primitivo giro de la filosofía analítica hacia el análisis del lenguaje. Casi podría leerse a Honneth como un complemento de la filosofía de Habermas, a nivel de teoría social, de lenguaje, de política, pese a los ajustes que requiere un modelo centrado en el reconocimiento. Honneth permanece en el paradigma de Habermas, no sin gestos de despedida. La ruptura sólo se habría producido si Honneth hubiera podido abandonar la comunicación o una teoría de la subjetividad inspirada por Mead, si hubiera recompuesto la teoría social de Habermas desde otras bases.

Mediante tal ampliación del modelo de Habermas, Honneth consigue al menos dos importantes desarrollos. Primero, una concepción de la evolución de las sociedades centrada en luchas sociales que afectarían al conjunto de la sociedad y que permitiría pensar en una intervención en la economía y en el aparato estatal, que ya no se conciben como subsistemas sociales al modo de TAC $^{1}$, es decir, neutrales y dejados a una lógica sistémica sostenida en medios deslingüistizados, irreductibles al entendimiento, pero que pueden intervenir en el mundo de la vida y colonizarla. En ese sentido, no bastaría con descolonizar el mundo de la vida como propone Habermas, más bien sería necesario colonizar los subsistemas sociales bajo la idea del reconocimiento. Y, segundo, una concepción de la justicia que ya no se pensaría centrada en la filosofía política o en la idea de igualdad, sino en las injusticias o en la falta de reconocimiento, lo que permitiría en parte incluir diferencias no reductibles a la noción de igualdad. Con ello, podría responderse a la crítica de Derrida y de

1. TAC, aquí y en lo que sigue, se refiere a Teoría de la acción comunicativa, de Habermas. 
las feministas, que habrían invocado un más allá de la justicia establecida jurídicamente. La filosofía social adquiere un peso importante frente a la filosofía política, pues insiste en las experiencias de injusticias, en el menosprecio, en las patologías sociales y en su diagnóstico adecuado. El precio relevante consiste en la necesidad de invocar el bien o modelos sociales morales para ese diagnóstico, según el modelo de Arendt.

Mi crítica se dirige a ese núcleo de reconocimiento que caracteriza en parte a la filosofía de Honneth, y que no deja de remitir también a algunos motivos habermasianos, respecto a los cuales avanza y retrocede al mismo tiempo. Avanza en el sentido de introducir una sensibilidad por el menosprecio y la injusticia, retrocede al no hacer patentes las opacidades y las dificultades sociales que una lógica sistémica sobrepuesta a la racionalización social pone ante el conocimiento y la integración social sin resolución fácil —como han indicado Nancy Fraser y Sheyla Benhabib, como el lacanismo de izquierda roza indirectamente y lo pone para pensar-. Queda en Honneth el resto de unas "patologías sociales", término que une lo individual con lo social, como ya hiciera Freud y luego Habermas, pero, al contrario de éste, ya no emerge el perturbador "malestar en la cultura", aunque sea en la forma de "colonización del mundo de la vida», en la dialéctica de la ilustración de Habermas, pese al escaso fatalismo que pretendería dejar los subsistemas como marco para la actividad social. Otras veces, Honneth lo desdibuja en favor de unas "paradojas del capitalismo», dentro de una fase de nuevo capitalismo «etificado" (2009b: 403), en un tono crítico más ligado a la lógica, como toda paradoja, y no a lo ético o a la salud, como en Freud o Habermas. Si realmente el capitalismo se ha apropiado de capacidades informales tras cierto paternalismo social surgido del estado de bienestar, en una oleada neoliberal, desmoronando la responsabilidad social, la solidaridad, cabría pensar, frente al reconocimiento honnethiano, en la necesidad de recuperar sistémicamente tales capacidades en favor de la responsabilidad y de una nueva política. No desde luego en un mercado con eticidad, como llega a sugerir el último Honneth, poniendo de nuevo más hegelianismo frente a Wellmer y su propuesta de una eticidad democrática. El nuevo malestar actual tras una cierta época de bienestar hace presente lo que no parece fácil domesticar, reformular, reconducir en el capitalismo según viejos modelos decimonónicos. Incluso tras la crítica habermasiana al modelo de una crítica social al estilo de Horkheimer, esa dialéctica de la ilustración de la primera generación, Honneth parece no aceptar la versión habermasiana de tal dialéctica, como si se pudiera superar hegelianamente. Sin embargo, no me parece fácil sustituir el esquema teórico social de Habermas gracias a una mera introducción del reconocimiento, pues queda la tensión entre racionalización sistémica y social — donde se suele olvidar la cultura como subsistema, justo a la sombra de un postmodernismo ya desinflado- - Honneth lo ha seguido intentando gracias de nuevo a Hegel, aunque sea invocando a Aristóteles y a la antropología filosófica, lo que hace visible de modo inmanente lo que, en el pensamiento de Honneth, se escapa del hegelianismo, pese a su fidelidad reiterada. 


\section{De vuelta a Hegel otra vez, pero cada vez de modo diferente}

Un hegelianismo de fondo persigue el desarrollo de la teoría crítica. Y, ciertamente, las deficiencias de tal pensamiento idealista la persiguen incluso en la interpretación de Marx, en la atención a la economía y las ciencias sociales, no sólo en la crítica totalizante del concepto de razón instrumental tantas veces señalada, sino tambien en los intentos posteriores de la teoría de la acción comunicativa. Como si hubiera sido una senda segura para pensar lo social o el Ser (social, desde luego) a la sombra de una gran tradición filosófica a la que Hegel daría término y conclusión preparando un cambio decisivo en la comprensión de lo social. Primero, la relevante influencia del Lukács que invoca al joven Hegel para proseguir en la presentación de Marx como filósofo un poco más allá de los manuscritos y de la ideología alemana. Es aquí un joven Hegel que estudia economía política inglesa para comprender una sociedad moderna. Más adelante, las diferentes formas de leer a Hegel de Marcuse, de Horkheimer, de Adorno, tan heterodoxas, tan antigehelianas: una freudiana, la otra schopenhauriana, la última schönbergiana y benjaminiana. Luego, la recuperación de la filosofía de Jena por Habermas (1989: 57), al invocar una alternativa para pensar la modernidad que ni se entrega al hegelianismo de derechas ni al nietzschianismo, que invoca la intersubjetividad que desarrolla y forma una voluntad colectiva, una razón comunicativa, aquello que, en TAC, ha proseguido Habermas, evitando el callejón sin salida de una filosofía centrada en la praxis o en un concepto de razón mermado, cambiando la estrategia de fondo de una filosofía focalizada en el sujeto/objeto o en la consciencia, cambiando el paradigma que fue válido en la teoría crítica. Hegel sigue dando la pista, y es la que recoge Honneth, pero esta vez fijándose en el reconocimiento como clave todavía más relevante. Habermas ha tratado de explicar por qué Hegel abandonó ese modelo de la intersubjetividad para entregarse a otro, el del saber Absoluto. Habermas invoca las limitaciones del viejo paradigma filosófico y afirma que, así, Hegel resolvía demasiado bien el problema de una modernidad en discordia consigo misma, cuyo centro es la reflexividad, pues la razón ocupa el centro y se vuelve avasalladora. Creo que es esa misma seguridad de la omnipotencia la que atrae y avasalla en todas las vueltas a Hegel, por mucho que blandan el tono de un Hegel contra Hegel mismo. Y no es una excepción el reconocimiento, pese a que el avance de Honneth parece alejarle de Hegel ya desde el principio, pese a que el recuerdo del sufrimiento, en realidad, le aleja de los vertederos de la historia hegelianos, de la misma filosofía de la historia de Hegel, más cerca de Benjamin y de Adorno, pero no sin resistencias — al estilo de cierto Habermas que los adorninados tienden a comprender como de una sola pieza e incluso, injustamente, como falsario.

En un primer movimiento, Honneth encuentra en el joven Hegel las claves para una noción de reconocimiento distinta y más valiosa que la contenida en la Fenomenología - esa dialéctica patética entre señor y siervo, que ha sido fuente de inspiración para una forma de entender las luchas sociales, que 
marcó al marxismo y a la teoría crítica haciendo prevalecer la categoría de trabajo como clave. Honneth identifica un reconocimiento más complejo en la filosofía de Jena que incluye aspectos afectivos, jurídicos y sociales (2009a: 218). En tal perspectiva, Hegel supera a Hobbes y a Maquiavelo por la vía de un concepto de lucha social donde el proceso histórico aparece como una sucesión dirigida de conflictos y disputas morales. Honneth detecta, en la forma de desarrollar el reconocimiento por el joven Hegel, indeterminaciones que remite a deficiencias en la teoría de la subjetividad, que es lo que intenta suplir Honneth muy cerca de Habermas con la ayuda de Mead, más que de Freud — que es lo que hizo Adorno- . Por tal camino, Honneth liga la teoría del reconocimiento a una teoría de la subjetividad, a una concepción de la intersubjetividad. Claro que es una teoría que pone en el centro la diferencia entre dos instancias en lucha, el I y el Me de Mead, a la sombra de un psicoanálisis americano centrado en el yo y que olvida la problemática del superyó freudiano, clave para el lacanismo como jouissance. Tal diferencia, pese a su relevancia teórica, no podemos seguirla en este texto.

Esta primera noción de reconocimiento, resultado de una ampliación retrospectiva frente a la reducción de Hegel por la vía del Absoluto, no deja de recordar la estrategia seguida por Habermas a la hora de redefinir el concepto de racionalidad para asumir las críticas radicales a la razón. Tres tipos articulados de reconocimiento riman con los tres tipos de racionalidad habermasianos; el reconocimiento afectivo, jurídico y social no deja de rimar con los componentes de la racionalidad cognitivo-instrumental, normativo y expresivo. La ventaja de tal ampliación reside en que ya no es fácil realizar una crítica del uso de la noción por invocación de lo que se menosprecia, ya que la misma crítica queda engullida por la noción ampliada como un aspecto suyo. Es la vieja estrategia hegeliana, tan denostada por los nietzschianos, pero también por un materialismo no ingenuo. De nuevo, la larga sombra hegeliana con su tricornio parece renovarse en una reflexividad que engulle lo que la limita. Es el peligro que los filósofos franceses de la diferencia han invocado una y otra vez hasta Derrida, el peligro de las variadas formas de logocentrismo, siempre renovado. La dialéctica en suspenso de Benjamin, como la dialéctica negativa de Adorno, intentaron salir de ese círculo idealista. Y Honneth ha tenido que reconocer que el reconocimiento como mero conocimiento es limitado y requiere de lo afectivo, de lo solidario. Por eso ha de situarse más allá del conocimiento, de la identificación del reconocer a alguien, hasta la aceptación de lados afectivos del otro, hasta tomar como reconocimiento lo que en realidad lo anticipa, lo constituye y lo cuestiona, respecto a uno mismo y a los otros.

El segundo movimiento relevante de Honneth consiste en llevar el reconocimiento hasta el punto de articular una ética del reconocimiento. A la hora de precisar el concepto de patologías sociales, no reducible a mera violación de principios de justicia, necesita vincularlo a la perturbación de un orden que se entendería como normal. Las injusticias tienen que ver con los miembros de la sociedad que se ven afectados por el no cumplimiento de normas establecidas, mientras que las patologías implican a la sociedad entera, en cuanto en 
ella no se da cumplimiento a lo que sería una buena vida en condiciones de socialidad. Al hilo de esta idea, Honneth desarrolla un modelo de comunidad postradicional en el que las relaciones de reconocimiento son decisivas y permitirían mediar entre liberalismo y comunitarismo. $Y$ es ahí donde precisamente usa a Derrida con Levinas para criticar a Habermas, en la idea de una ética del cuidado que sobrepasaría la ética del discurso. Honneth apunta hacia una solidaridad que supera la imparcialidad y el formalismo de un sometimiento a leyes, en dirección hacia unas relaciones afectivas que no presupondrían derechos establecidos. Aquí el reconocimiento trata de recuperar el cuidado y la solidaridad que, por otras vías, han reivindicado Derrida con Levinas. Honneth invoca una moral del reconocimiento para integrar tanto la idea de justicia como la de una vida buena, en un gesto entre Aristóteles y Kant. Esto llevó a Honneth de vuelta a Hegel, como si fuera necesaria una revisión de su misma estrategia, como si, por este camino, la inseguridad del avance le obligara a revisar la perspectiva. Y vuelve al Hegel de la Filosofía del Derecho, al que piensa el Derecho y la indeterminación a la que se ven abocados los individuos cuando, pese a tener libertad negativa, no ven reconocidas sus capacidades en la familia, en la sociedad civil, en el Estado. Honneth despliega la noción de una libertad comunicativa, más positiva y determinada, que daría la clave para matizar el concepto de reconocimiento, ahora con una intención ética. El reconocimiento mediante ese avance teórico de Honneth ha adquirido rasgos de lo que supone un trato con el otro que le asignaría un estatus de sujeto y no de mero objeto de una racionalidad teleológica.

En otro paso decisivo, Honneth va todavía más allá de la primitiva reformulación del reconocimiento y lo redefine por una vía más existencial. Lo hace como respuesta a las críticas vertidas por Nancy Fraser (2006), pero tambien por Heikki Ikäheimo y Arto Laitinen (en Brink-Owen, 2007). Eso conduce a Honneth a evitar el dualismo entre justicia y distribución, tomando las experiencias de injusticia como clave de los conflictos; por otra parte, vincula el reconocimiento a un comportamiento que respondería racionalmente a cualidades evaluativas que aprendimos a percibir en nuestra socialización. El reconocimiento se articula con las experiencias de injusticia, con el sufrimiento social $y$, al mismo tiempo, con la idea de una vida buena. Pero tambien Honneth reflexionó sobre la relación entre reconocimiento e ideología: el falso reconocimiento. Ese era uno de los puntos más débiles ante una crítica política que destacara el lado positivo de su planteamiento, la escasa atención a estrategias de un poder que imitara engañosamente el reconocimiento. Honneth pone aquí la clave no en el viejo concepto marxiano de "falsa consciencia», sino en que la diferencia entre un adecuado reconocimiento y otro ideológico sólo se haría visible en la realización institucional que da cobro a ese reconocimiento, en la práctica y no en la pura construcción de ideas. Cuando no se realizan los requisitos materiales que establecerían un reconocimiento de algo o de alguien, entonces no habría tal reconocimiento, sería más bien la promesa incumplida de hacer lo que se pretende re-conocer (lo que es bastante frecuente en los programas políticos de los grandes partidos). En todas esas matizaciones del 
reconocimiento, Honneth se ve conducido a afirmar la primacía del reconocimiento sobre el conocimiento. Y, como un punto de inflexión en su obra, trata el fenómeno de la cosificación, recogiendo la formulación clásica de Lukács.

Honneth critica y reconstruye la noción lukácsiana de cosificación como olvido del reconocimiento. Finalmente, se muestra lo que sería una noción de reconocimiento relevante para entender las otras formas: un reconocimiento existencial que daría el fundamento para el afectivo, el cognitivo-jurídico y el social. Y es algo relacionado con la constitución del sujeto humano, con su entrada en el lenguaje y en la intersubjetividad; aquello que no se debería olvidar y que da la clave para la interacción social: cómo fue cuidado para convertirse en sujeto humano. Pero tal vez debería preguntarse si un reconocimiento anterior al conocimiento sería conocimiento u otra cosa, al modo en que las ideas platónicas parecen necesitar una especie de vida anterior, la que un esclavo podría recordar con la mayéutica adecuada. Menos idealismo es lo que permite una concepción del sujeto y del lenguaje no reducida al mero conocimiento, a la razón y a la significación, a la consciencia y a la discursividad. Nos obliga a no olvidar las condiciones que harían posible un sujeto antes de ser reconocido, de poder verse como reconocido.

\section{Reconocimiento como olvido de cierta cosificación}

Al definir la cosificación como olvido del reconocimiento, Honneth, en un gesto que habría hecho sonreír a Lukács ${ }^{2}$, lo relaciona con la cura heideggeriana, con la implicación existencial, finalmente, con una forma de praxis incorrecta (2007: 55). En el saber de cosas y en el conocimiento de otras personas, se pierde o se olvida la consciencia de que ambos momentos se deben al reconocimiento previo. Pero no es un olvido total, sino una pérdida de atención al reconocimiento previo que sustenta el conocimiento. Honneth despliega una reflexión sobre este tipo de olvido que es una disminución de la atención en cuanto praxis unilateral que persigue enérgicamente un propósito o como esquemas de pensamiento que realizan una interpretación selectiva de nuestra praxis. Se trata de unilateralidad o de prejuicio. Lo que permite incluso entender la reificación de la naturaleza, como olvido de lo que significaron los objetos naturales para las personas que amamos, para las personas de referencia. Honneth añade la cosificación de uno mismo como olvido de un reconocimiento anterior en nosotros mismos, que permitió articular sensaciones y deseos, e invoca una exploración lúdico-creativa de las propias necesidades, que remite a Winnicott. Apunta a una apropiación de los propios deseos como defensa de la cosificación de deseos y de sensaciones propias, en las actitudes detectivescas o constructivistas. Se trata de no olvidar la autoaprobación pre-

2. ¿Nos pide Honneth que leamos ya a Lukács con la mirada puesta en Heidegger y olvidando la alusión lukacsiana del prólogo de Historia y consciencia de clase al Goldman que vio en Ser y tiempo una respuesta conservadora al Lukács comunista? Quizás sea mejor leerlo desde una perspectiva benjaminiana, puesto que sitúa la cosificación más lejos. 
via que nos constituye. Por esa vía de la cosificación a tres niveles, que calca y despliega su teoría del reconocimiento, apunta Honneth a una crítica social que no puede reducirse a medir el orden normativo por principios de justicia, que requiere atender a otros fallos, a las patologías sociales, a los olvidos del reconocimiento por una normatividad que no es necesariamente injusta, sino cosificante en nosotros mismos, en las relaciones humanas, en el conocimiento. $\mathrm{Y}$, al final, la cosificación se sustenta en una teoría de la subjetividad que se basa en Mead y se tiene que ampliar gracias a Winnicott.

El olvido del reconocimiento no se apoya tambien en una teoría del olvido o en una filosofía de la memoria, aquella que persiguieron Benjamin con Adorno tras Bergson y Proust y que adquiere relevancia en la distinción entre recuerdo y memoria, rememoración y recordación, entre Erinnerung y Gedächtnis. ¿Es el olvido del reconocimiento lo que se interioriza como memoria involuntaria o, simplemente, se mueve gracias a la astucia de una memoria voluntaria que deja los agujeros que le interesa según una trama de poder? Una cosa es un comportamiento inconsciente que moviliza a los participantes en lo social cual objetos o mercancías, no lejos de lo que el fetichismo de la mercancía saca a la luz en Marx o que Freud piensa por la vía del narcisismo o la perversión; y otra, un comportamiento estratégico que moviliza el aspecto ideológico del reconocimiento por las vías de una ingeniería social o por la de una democracia conducida por grupos de poder. Honneth no parece reflexionar sobre la diferencia entre memoria voluntaria e involuntaria y las implicaciones histórico-sociales, no sólo psicológicas, un tema central en el Benjamin último, cuya reflexión sobre lo cosificado llegaba hasta el motivo kafkiano de Odradek. Se necesita una filosofía del olvido que haga presente el desconocimiento que habita en lo social y en nosotros mismos.

Pero, como no podemos seguir ese desarrollo teórico en este texto, indicaré algunas pistas. Esa teoría del olvido no estaría tan alejada de la teoría social y del sujeto, como lo está el reconocimiento de raíz hegeliana, pues aparece en la socialización y la enculturación, tambien en la entrada del niño en el lenguaje por división del sujeto y por alienación de su ser, donde se haría pensable tal olvido, en una tensión entre sociología y psicoanálisis irreductible a mero reconocimiento. Se trataría de recordar lo que nos convierte en seres sociales frente a una cosificación que entierra, primera o secundariamente, el reconocimiento, recordar lo que antes de cualquier lucha social nos hace humanos. Es hacer presente la división y la alienación que constituye a un sujeto que habla. De ninguna manera pueden convertirse en conocimiento, si tiene algún sentido preciso, tampoco en un reconocerse como tal. Se trataría de atender a algo peculiar, que puede retomarse, intuir, verse en el rostro de otro, en nuestras manías y síntomas, en una dimensión inconsciente pocas veces accesible, entre el amor que nos posee como el odio y la transferencia positiva y negativa. Lo inconsciente no puede ser consciente, tal es la tesis central de Freud que diferencia su obra de la noción romántica que se asemeja a lo inconsciente. Con la referencia al lenguaje es lo que separa al psicoanálisis freudiano de los juegos del nigromante con la hipnosis, pero tambien lo que 
le separa de una psicología que no vaya hasta sus condiciones de posibilidad, hacia una metapsicología.

El énfasis en la idea de reconocimiento, pese a lo que permite aportar para comprender cierta socialidad, puede llevar a un olvido de la cosificación que constituye a los seres humanos como seres sociales y lingüísticos, a olvidar que no hay sujeto sin objetualidad constituyente, irreductible. La cosificación no es traducible sin pérdida como conocimiento o consciencia, tampoco como reconocimiento, éste la presupone de modo inalienable. Es el reconocimiento lo que significa un olvido de la cosificación, nos entrega a la intersubjetividad y al lenguaje, nos aliena en ellos tras la división que constituye la subjetividad. En el reconocerse o ser reconocido, a cualquier nivel, hay que olvidar lo que, siendo cosa, nos condujo a lo que somos, lo que nos hizo hablar, lo que nos sigue haciendo hablar, lo que deja su huella en el lenguaje a la contra de cualquier conocimiento, dando entrada a pulsiones y deseos, a una dimensión de goce no reducible al símbolo, olvidar todo eso para creerse que uno es solamente ese algo reconocido como individuo, como trabajador, como ciudadano, como lector, como ser sexuado.

\section{Más allá del reconocimiento: el desconocimiento del otro como condición clave}

Tal vez habría que despedirse de Hegel, no sólo por la necesidad de incorporar productivamente lo que no es mero conocimiento, ni puede ser reconocido bajo tal perspectiva, que es la de una vuelta a lo ya conocido, a saber, el reconocimiento. Despedirse de Hegel consistiría tambien en evitar el etnocentrismo de Hegel, no sólo el institucionalismo o el logocentrismo. Por un lado, considerar el lenguaje en su aspecto más ligado a lo productivo, a una escritura abierta al significante, que es, por otra parte, como De Man ha intentado leer ciertos pasos de Hegel en contra de la interpretación dominante, que no está lejos de la de Honneth. Por otro lado, como ha hecho Benhabib (2006: 271), mostrar en el detalle, allí donde Hegel reflexiona sobre las mujeres, las insuficiencias de tal pensamiento. Despedirse actualizando aquello a lo que se le dice adiós, despedirse antes de comenzar a conocer de otro modo. Despedirse del reconocimiento en el lenguaje y en lo psicosocial, no por la vía de menospreciarlo, sino del aprecio que lo muestra como insuficiente en lugar de estirarlo para que deje de serlo. Volviendo a repetir, pero de modo no hegelianizante, sin las cortapisas de lo ya reconocido, el gesto de Honneth con el que el reconocimiento intentó superar la idea convencional de justicia, aquella que tiene en Rawls su representante actual, la igualdad como clave para la democracia, y la teoría social que divide su objeto en sistemas y mundo de la vida. Como antes Habermas lo hizo con la idea de una racionalidad comunicativa frente a una racionalidad unilateral.

La misma evolución de Honneth es la prueba de las insuficiencias del reconocimiento para dar cabida a una comprensión adecuada de lo social y del mismo malestar que moviliza las resistencias de los sujetos menospreciados. 
En cada uno de los avances teóricos de Honneth, se produce una modulación del concepto que lo aleja o lo vuelve a acercar a su formulación, a las formulaciones de Hegel (en Jena, en la Fenomenología, en la Filosofía del derecho). Podría seguirse modulando como una etiqueta que se aplica a una complejidad casi inabarcable, pero quizás fuera mejor despedirse de tal concepto para determinados usos. No estirarlo hasta que incluya casi la ontogénesis humana o todo lo que envuelven las relaciones sociales. Ocurre como en el concepto de racionalidad en Habermas, hay un punto donde se muestra la dificultad de incluir aspectos que, tradicionalmente, se separaban de lo racional. La racionalidad comunicativa tiene el rasgo de un movimiento que lo devora todo, dejando poco espacio para lo no comunicativo y a su vez no irracional. Habermas ha aceptado que no es válida una teoría expresivista del arte, pero, aunque ha remitido a Wellmer, no ha pensado las modificaciones que implicaría eso para el conjunto de la TAC. Menke (1997: 289) ya planteó una objeción relevante a la teoría de Habermas basándose en la soberanía del arte, en un movimiento complejo donde se acerca a Derrida y Bataille para invocar la estética de Adorno con implicaciones teórico-sociales, como instancia de crítica a la razón. Algo semejante se podría decir del concepto de reconocimiento, no solamente aplicado al arte como establece una estética actualizada (Aguilera, 2002: 142), cuando se trata de poner a su cuenta lo que no tiene que ver con una forma de conocimiento, cuando se moviliza como algo anterior a los mismos procesos de identificar algo, de conocerlo, de volverlo a considerar. Si, para el reconocimiento, cabe invocar el desconocimiento en el que se sitúa quien se socializa o entra en una cultura, en procesos de subjetivización que suelen describirse de otra manera, tal vez haya llegado el momento de reconocer las limitaciones de tal concepto. Y abrir tal estrategia centrada en el reconocimiento a lo que la impulsa y a lo que la limita: el desconocimiento que implica un reconocimiento del otro a todos los niveles, incluso aquellos que no podrían entrar en la tipología de Honneth, no casualmente triádica, si se atendiera a lo que la microhistoria o la microsociología permiten entrever después de Hegel, más cerca de Benjamin, en la fisiognómica social.

Partir del concepto R para seguirlo, problematizarlo y llevarlo hasta una especie de concepto transformado, R', "superreconocimiento" si se quiere, es una estrategia cuasihegeliana que, en realidad, intenta de modo insuficiente atender a lo que se escaparía al idealismo, no sólo al absoluto, sino tambien al lingüístico. Hay otro modo de proceder que creo ayudaría mejor al mismo desarrollo de Honneth al darle más libertad, la que se obtiene mediante la fidelidad a otros desarrollos no estrictamente hegelianos, más marxistas y adornianos. Deja de lado la seguridad avasalladora de una razón hegelianizante, aunque ahora ya se ha metamorfoseado en gran parte en cientismo, como una variante del idealismo absoluto. Consistiría en despedirse del reconocimiento, del reconocimiento del mismo Hegel en una tradición alemana hegelianizante, dando cabida a una tradición más materialista, la que, por ejemplo, puede seguirse en Benjamin y Adorno y no se olvida del arte, de lo estético que penetra en lo social, tampoco del sufrimiento social. Desde luego, la decons- 
trucción lo ha intentado de modo peculiar, poniendo todos los recursos de la metonimia en favor de lo que se escapa a la dialéctica idealista. Sin embargo, es en la historia misma de la teoría crítica donde hay material para devanar ese hilo de manera menos hegelianizante, como se hace visible en la dialéctica en suspenso de Benjamin.

Aquí le tomamos la palabra a Honneth, cuando invocó la necesidad de articular la tensión entre una ética del discurso de orientación habermasiana y una ética del cuidado de origen levisiano-derridiano, aunque, sorprendentemente, no trató esa tensión como dialéctica, buscando un lugar donde se superaría, donde se abriría una perspectiva posthegeliana. ¿¿ería una dialéctica en suspenso benjaminiana? En los últimos desarrollos de la teoría crítica, se ha hecho presente gracias a Wellmer, con una atención peculiar a la estética de Adorno, un modo de proceder menos hegeliano que el curso principal de la teoría crítica. Honneth ha tenido que constatarlo, por ejemplo, en la atención a la fisiognómica social de Adorno o en su nueva lectura de Dialéctica de la ilustración, ya posthabermasiana, o en la relevancia otorgada a la eticidad democrática de Wellmer. Pero Honneth sigue afirmando su hegelianismo frente a Wellmer. Sin poder entrar en tal debate casi de escuela y ya fuera de ella, en una perspectiva cosmopolita localizada en Europa, se hace necesario invocar la tensión entre una filosofía centrada en el conocimiento, en el lenguaje como comunicación, en el sujeto que entra sin pérdida y, felizmente, en la intersubjetividad, y otra filosofía que pone en el centro lo inconsciente, el lenguaje como significante y goce, un sujeto que se divide y aliena a la hora de entrar en el lenguaje y en la intersubjetividad, lo que genera una opacidad irresoluble para tal sujeto escindido, para el ser que habla, en él mismo y en sus relaciones con los otros. Pero el ser parlante lacaniano también es un ser social, como muestra el dominio sin dominación en el que se mueve la terapia analítica, una praxis social. Seguramente, Habermas con Honneth podrían haber atendido a la perspectiva que abre un psicoanálisis como el lacaniano, al que Adorno mismo reclamó atender al final de su vida, en las lecciones de introducción a la sociología de 1969 (1996: 138). Habría sido mucho mejor que Winnicott, que es el modelo clave para la comprensión del reconocimiento existencial en Honneth, es decir, lo que estaría más allá del reconocimiento convencional. Ya Horkheimer intentó pensar a partir de la tensión entre Kant y Sade, pues hacía presente la posibilidad de una inteligencia puesta al servicio de la voluntad de goce y su efecto social. Tambien Adorno constató la tensión irresoluble entre psicoanálisis y sociología para mostrar una socialidad irreductible al conocimiento. La noción de superyó es decisiva para distinguir a Mead de Freud, como la metáfora paterna diferencia a Winnicott de Lacan y deriva en formas de clínica distintas. Tales perspectivas sugeridas darían claves teóricas para avanzar en otra manera de entender la socialidad, la justicia, el sufrimiento social, esa socialidad que emerge como reconocimiento o como menosprecio, la que se abre en la constelación postnacional, en lo cosmopolita. Es esa tensión lo que me parece clave para poder pensar productivamente una apertura radical al otro. 
En Honneth, es posible ver un arco de pensamiento donde viejos supuestos que inspiraban su crítica al poder o al mismo Adorno se van transformando hacia el final con la ayuda de Wellmer, hasta incorporar importantes reflexiones del Adorno más filósofo. Poner al arte como una esfera de la cultura que hace posible criticar la razón en una soberanía extraña del arte — no muy lejana de Bataille y de Derrida, por mucho que se recomponga como interna a la cultura moderna-, ayudaría a entender una apertura al otro, al otro de la razón como a los demás seres humanos, que no alcanzaría el reconocimiento. Especialmente cuando se pasa a una constelación postnacional donde ya difícilmente puede encontrarse un afuera al que remitir ciertos valores o culturas, incluso ciertas prácticas sociales o formas de ser. Emerge otra topología en el espacio cosmopolita ya postnacional, donde la multiplicidad inabarcable se vuelve interna a procesos de socialización ya cosmopolitas. Y aquí trato de sugerir al lector que un problema tan especulativo como el del reconocimiento o su crítica afecta profundamente a otras reflexiones o discusiones como la que permite plantear el cosmopolitismo en la actualidad.

\section{Inclusión del otro, no un mero reconocimiento}

Frente al reconocimiento, se puede invocar la aceptación del desconocimiento en el trato social, de lo extraño en sentido radical. Se trata de una inclusión del otro que no implicaría reconocimiento, que permitiría el desconocimiento en el otro en el reconocimiento, de lo no respetable del otro en el respeto. $\mathrm{Ni}$ reconocimiento ni mero respeto, se trata de algo más en la confrontación entre seres humanos en un espacio ya cosmopolita, donde no habría dentro ni afuera que pudiera marcar las viejas fronteras, las de las naciones o las del sujeto pretendidamente idéntico a sí mismo. Se trata de la inclusión del otro en el espacio de una pretendida identidad cuya opacidad queda a la vista como inconsciente o arte o movimientos sociales, como espontaneidad imprevisible, característica de un sujeto humano. Inclusión del otro en unas relaciones sociales marcadas por lo cosmopolita y que significa profusión inabarcable de mundos de vida, culturas, formas de vida buena, costumbres, lenguajes, incluso en los espacios nacionales que algunos todavía pretenden idénticos a sí mismos. Una nueva torre de Babel moderna, esta vez un conjunto de rascacielos, donde ningún ser humano debiera ser excluido del esfuerzo por ascender hasta el cielo: ¡lo hay o surgiría del esfuerzo conjunto e irreductible hacia arriba, hacia una sociedad mejor?

Mejor sería hablar de inclusión del otro que de reconocimiento, pues la inclusión permite apuntar a las limitaciones de un mero conocer. Ya Honneth en 2011, en su Das Recht der Freiheit, al invocar un nosotros en el que cristalizan una multiplicidad de sujetos (relaciones personales, relaciones económicas, relaciones políticas), amplía de nuevo la perspectiva del reconocimiento o lleva hacia la explosión de la misma. Pero quedan rasgos de una reflexión sobre Europa, ligada al concepto de nación de raiz hegeliana, que apunta en una dirección diferente a la de Derrida en su El otro cabo, cercana finalmente 
a la de Habermas en lo político. Me pregunto si Honneth realmente apunta a un reconocimiento de Europa en la constelación postnacional, entendida como luchas cosmopolitas, o si remite a una libertad que debería prosperar en ese ámbito más allá de la igualdad y que debería lograrse con la ayuda inestimable de Europa, sin dejar de incluir a cualquier otro en tal constelación postnacional. Tal vez la idea de una constitución cosmopolita, defendida por Habermas contra las tentaciones schmittianas, que acabaría con las debilidades del derecho internacional en lugar de proseguirlo con dureza, sea lo decisivo, pero tambien porque permitiría la inclusión de todos los habitantes de este planeta, sea cual sea su condición, sin distinción de culturas o de actitudes. ¿¿No implica eso un reconocimiento que admite el desconocimiento del otro en cuanto sujeto? ¿No lo sobrepasa admitiendo las opacidades que atraviesan cualquier sujeto humano y sus relaciones sociales?

$\mathrm{Al}$ invocar aquí una concepción del lenguaje y de la intersubjetividad diferentes a las supuestas por Honneth, se quiere hacer presente la necesidad de aplicar otro giro lingǘ́stico en el paradigma habermasiano, del que no parece haber salido Honneth. Se trata de un cambio que conduce a una apertura al otro más radical y tal vez la única que parecería articulable con una perspectiva cosmopolita, donde ya no son las luchas sociales dentro de una cultura o sociedad lo que daría la clave de la evolución y el progreso moral, sino la confrontación entre culturas y sociedades en un espacio donde ya no queda un afuera y donde diversas ideas de vida buena se confrontan; diversos valores y normas compiten, y mundos de vida alternativos tienen que vivir conjuntamente. $\mathrm{Si}$ no se defiende el planteamiento de Carl Schmitt y una lucha de civilizaciones, al que se oponen Habermas con Derrida frente a una izquierda tentada por la invocación del enemigo como clave de lo político, hay que buscar alternativas cosmopolitas para pensar una socialidad hipercompleja, más allá del mero reconocimiento, de las luchas sociales, de la vieja política de la enemistad, incluso la corregida hegelianamente.

En el mismo pasado de la teoría crítica, puede detectarse un movimiento al que no ha sido del todo insensible Honneth y que ha modulado últimamente su particular hegelianismo. Fue ya Adorno quien se despidió de Hegel más brutalmente: un hegelianismo antihegeliano que encuentra en las grandes obras de Hegel, no en intentos juveniles, sino en la Ciencia de la lógica misma leída desde dentro como negación dialéctica que partiría del algo y no del ser, el modo de escapar de Hegel para seguir por Marx y Freud, por las ciencias sociales y la crítica de la cultura. Pero si la dialéctica negativa parece el esfuerzo adorniano para terminar con Hegel, haciéndole justicia, el menos hegeliano de los frankfurtianos, Walter Benjamin, haría presente ese alejamiento radical de Hegel en un proceder micrológico, deconstructivo, en una noción de historia sin astucias de la razón. De modo diferente, Habermas y Honneth han vuelto una y otra vez a Hegel, aunque siempre negándolo, como ya tambien lo hizo Lacan hasta que, en los años setenta, rompió con la idea de reconocimiento. Todos ellos tentados por el abismo hegeliano de la razón, por su omnipotencia, aunque sea denegada. La tentación de lo Absoluto siempre sobrevolando 
el cielo hegeliano, la tentación de una razón omnipotente a la que no se le reconoce sus procesos autoinmunitarios, cancerígenos.

El concepto de reconocimiento no permite suplir las deficiencias detectadas por Honneth en el giro pragmático de Habermas, que trató de corregir la perspectiva analítica enfatizando la comunicación, o en el enfrentamiento de Habermas con cierta filosofía francesa, al menos hasta encontrar afinidades relevantes con Derrida. Tampoco parece permitir la idea de reconocimiento ir más allá desde un punto de vista teórico-social, pues Honneth ha admitido que, pese a intentarlo, no encuentra una alternativa general a la construcción habermasiana, aquella que apunta a suturar la fractura entre mundo de la vida y sistemas sociales, como si la colonización del mundo de la vida que traduce el diagnóstico weberiano pudiera ser resuelta por la vía de un dominio de tales subsistemas desde las luchas sociales, como si invocando a Foucault se pudieran compensar las limitaciones de Habermas. Se necesitan más pasos y, al mismo tiempo, un cambio de perspectiva que retoma algo perdido por Habermas en la propia tradición de la teoría crítica, de lo periférico y de lo más central, de Benjamin y de Adorno, de Fromm y de los economistas alternativos. Se necesita de una tradición francesa que representaría mejor Derrida que Foucault, corrigiéndola ciertamente como ya hacía Honneth al invocar a cierto Adorno. En lugar del giro hacia el reconocimiento honnethiano, podría reformularse mejor por la vía de la inclusión del otro, que Habermas ya ha nombrado ${ }^{3}$, pero tambien por la hospitalidad, que exige más frente a la mera tolerancia, especialmente donde no todos los seres humanos tienen iguales derechos y no todos pueden o quieren luchar por el reconocimiento.

Apuntamos hacia una inclusión del otro, que ni siquiera en Habermas presupone homogeneidad o reducción a la mayoría, pero que incluyera, además, la hospitalidad, la que acoge a aquellos extraños que ni simplemente pueden luchar por el reconocimiento o, simplemente, comunicarse de modo pragmáticamente eficaz. Se necesita remitir a una concepción de lo político, no meramente centrada en lo jurídico o en los movimientos sociales, abierta a una perspectiva donde la vieja política vinculada a lo enemigo y lo hostil se viera forzada a pensar una política de la amistad, a la que ha apuntado Derrida. No cabe duda de que quedan muchos espacios de luchas sociales, por la distribución de recursos como remarcó Fraser y no tanto por el mero reconocimiento, pero el planeta podría agradecer otra manera de hacer política, que pusiera el enemigo en otro lugar, en la naturaleza realmente hostil, especialmente aquella que emerge como segunda naturaleza en la industria, más que en los otros. El viejo tema del malestar de la cultura lo remueve, aunque ya no se pueda invocar la pulsión de muerte como de modo dubitativo hacía Freud.

Pasar del reconocimiento a la inclusión del otro debiera permitir sobrepasar la idea de luchas sociales, no sólo por la escasa simetría del poder entre

3. «[...] inclusión significa que dicho orden político [autolegislación que incorpora por igual a todos los ciudadanos] se mantiene abierto a la igualación de los discriminados y a la incorporación de los marginados sin integrarlos en la uniformidad de una comunidad homogeneizada» (1999: 118). 
grupos a la que conducen tales luchas, sean de clases sociales, de etnias, de naciones o de bloques de civilización. Tal vez por la vía de una paz perpetua conseguida tras una constelación cosmopolita, donde la protección y el cuidado de todos los seres humanos fueran condición y fin de una sociedad en la que pudieran ser limitados los diversos subsistemas sociales. Lo que recuerda que, en Kant y su cosmopolitismo, hay algo más actual que en Hegel. Emerge una normatividad que, como indicara Bauman respecto a la falta de lo moral en la sociología en su trabajo sobre la modernidad, no hay que esconder tras una neutralidad weberiana: nada de luchas sociales, conservadurismo radical en lo social, respeto a la integridad, la autoconservación, la renta mínima vital; fin del estado de la naturaleza que ha proseguido en el capitalismo, fin de la historia como catástrofe continua (Benjamin). Pero tal inclusión radical del otro no debería excluir el dinamismo sin límite, no el de un experimentalismo económico que pagan los muchos, sino el de una reflexividad sin freno y de luchas intelectuales, en el conocimiento y el arte, que abrirían la posibilidad de lo nuevo, especialmente cuando ninguno de los participantes en tales luchas se viera afectado en su superviviencia. La inclusión del otro debería ser más absoluta que cualquier tentación de vuelta al absolutismo del saber hegeliano. Lejos de la homogeneización a la que apunta cualquier política de la enemistad, al definir lo nuestro como la negación de lo enemigo. En vistas a una racionalidad y a un conocimiento que se pondrían al servicio de lo que las impulsa, de las vidas humanas a las que debieran servir, de la evitación del sufrimiento como máxima prioridad. Allende la racionalidad comunicativa, atención a algo no comunicativo, allende el reconocimiento como atención a lo que, en el otro, se mostraría como desconocido. Se trata de poner en el centro una hospitalidad particular.

Y la forma más clara de hacer aparecer en una vía lingüística tal inclusión del otro en lugar de un mero reconocimiento es, a nivel cosmopolita, la traducción, pues en ella se haría presente cuando se toma como fiel a lo que transmite - y no a lo ya conocido que se podría o no reconocer en el otro-, que el otro como tal puede ser difícil de reconocer. Haría necesario reconocer que lo desconocemos profundamente, que tenemos que forzar el lenguaje para que, simplemente, quede el hueco donde pueda aparecer ese algo desconocido. Dar hospitalidad al otro, al lenguaje del otro en el lenguaje propio, al ser del otro que, estando alienado en el lenguaje, no hace sino mostrar su división, el desconocimiento en sí mismo que lo mueve, que nos mueve. En esa frontera que rompe sus aduanas como fronteras impermeables, hay algo decisivo. Una política de la traducción daría la clave: politización de la traducción, no mera traducción de lo político, de la democracia, de lo cultural, de una cultura a otras. Inclusión de todos los seres humanos bajo el viejo concepto kantiano de humanidad y no del de nación hegeliana.

Tal vez la razón comunicativa sea insuficiente para pensar la nueva situación cosmopolita, tal vez TAC sólo sirva para describir una sociedad avanzada, pero no en confrontación con las demás en el espacio mundial. Sea como fuere, el avance teórico de Habermas ha pasado por centrarse en el 
derecho, en una teoría de la democracia que hace valer lo constituyente como clave de la legitimidad de lo político, generalizando implícitamente muchas de las construcciones de su teoría de los años ochenta, aunque reconociendo las debilidades que otros han ido señalando. Sin embargo, la discusión más filosófica no ha quedado cerrada por la formulación de una superrazón, por la razón comunicativa que superaría viejos conceptos unilaterales de razón, en realidad, ha abierto a la necesidad de incluir algo que fundamenta la razón, esa misma o la otra, una socialidad irreductible a su mera racionalidad. No todas las críticas han sido irracionalistas. Sirva como ejemplo clave la crítica de Menke a la racionalidad comunicativa que emergería en la idea misma de una estética negativa. Tampoco creo que el reconocimiento bastara para pensar lo cosmopolita, al menos no al modo del Hegel que pudo invocarlo dentro de la nación y para un sujeto que se constituye en la dialéctica idealizante de un yo que alcanza al nosotros o de un ser que, mediante el paso por la nada, llegaría hasta el punto más alto. Tampoco bastaría un superreconocimiento ( $\left.R^{\prime}\right)$ que poco puede hacer con lo olvidado, lo desconocido, con el otro humano como algo irreductible al yo, con otras culturas o sociedades, con otras formas de vida que no se reducen a mero conocimiento ni significación, ni comunicación, ni son flujos cognitivos. Ningún «reconocimiento» puede asimilar bien el desconocimiento irreductible que lo otro, en su radicalidad, trae ante un sujeto tardomoderno, en una sociedad hipercompleja. No sólo porque lo que impulsa ese mismo conocimiento, como sujeto social o como objeto de saber natural e histórico-social, sea irreductible en cuanto la misma historicidad de tal saber hace presente, sino porque el mismo conocimiento se ha convertido en particularmente inquietante, sorprendente, peligroso, en la física atómica, la ingeniería genética, en las máquinas complejas. El Fausto de Goethe, el Frankenstein de Mary Shelley, innumerables películas recientes lo traen a reflexión como algo inquietante. Es el mismo conocimiento, ya irreconocible, junto a los seres humanos que intentamos conocer en su socialidad y subjetividad, junto a uno mismo, lo que ya no podemos reconocer, ni superreconocer. Pero podemos seguir hablando de ello, dejarnos penetrar por ello, incluir a ese ello, dejar que allí donde ello estuvo pueda uno llegar a ser con tantos otros, de modo cosmopolita, pese al nuevo malestar en la cultura, ya postfreudiano, más terrible que el que Simmel con Freud trajeron a reflexión.

\section{Allende el reconocimiento: traducción como apertura cosmopolita al otro}

Para el idealismo, del absoluto al lingüístico, del cosmopolita al nacionalista, la traducción es mera transferencia de información, algo transparente cuando es eficaz. Por eso es tan importante el reconocimiento, puesto que, simplemente, mostraría, en toda relación intersubjetiva, incluido el lenguaje a traducir, lo que hay que reconocer como ya susceptible de conocimiento. Incluso un superreconocimiento, un reconocimiento existencial, daría el paso consecuente hasta poner la misma existencia como algo ligado al conocimiento, incluso hasta las 
luchas sociales serían parte de una lucha por un conocer en los otros. Pero algo obliga a negar ambos extremos centrados en el conocimiento, en gran parte deslingüistizado, desmaterializado. Si resulta que la traducción no es mera transparencia, sino un esfuerzo sin garantía alguna, un empeño en mostrar lo ajeno y lo extraño como tal sin reducirlo a lo ya conocido, sin pretensión de reconocerlo en nosotros mismos, tampoco el otro ya no puede ser siempre en realidad uno mismo, idéntico a uno mismo tras la apariencia de no identidad, ni siquiera aparecería como un hermano al modo de la consigna de los revolucionarios franceses a finales del siglo xviII. Cuando se niega que la traducción sea algo meramente transparente o instrumental, al modo de Benjamin y lo que concibió como tarea del traductor, las cosas cambian. Se hace presente que las luchas fraticidas son las más sangrientas, las luchas por las mínimas diferencias son las más indiferentes a un otro que sólo se reconoce de modo estratégico, no como un otro nunca idéntico a uno mismo, se muestra la posibilidad de un sentimiento de culpa que persigue al sujeto no idéntico a sí mismo. Más allá de cualquier reconocimiento, está la posibilidad de una identidad por la no identidad, a la que el lenguaje da su medida cuando se lo ve como algo más que mera significación o comunicación, cuando se comprende tanto la socialización y enculturación que presupone, como la división del sujeto y su alienanción, así como el goce que lo sustenta más allá de lo meramente instrumental. Otra filosofía del lenguaje emerge para un conocimiento sensible a la otredad radical, desde Freud al menos, desde Benjamin y Adorno, en Derrida y tantos otros, a la que no haría justicia el hegelianismo ni la razón comunicativa.

La vieja confusión de lenguas con las que pretendidamente Dios desbarató el esfuerzo de la torre de Babel, los edificios de metal y vidrio que rascan el cielo en toda la Tierra remiten hoy, en un contexto cosmopolita, a la traducción. Si la teoría social introduce la problemática de la traducción en la perspectiva cosmopolita, en la comunicación global, en los flujos de información, no lo hace necesariamente como algo transparente e instrumental. La forma de traducir y de comprender las traducciones en la profusión de intercambios e interacciones culturales, nacionales, internacionales, entre culturas y religiones, no es única, aquí el mero reconocimiento, como antes la tolerancia, permiten pensar en limitaciones importantes en la relación, en la apertura, en la inclusión de los otros. La traducción, como la relación con los otros respecto a la tolerancia, requiere de mucha más hospitalidad, de una aceptación de lo desconocido, del desconocido al que no se le exige ni siquiera el nombre.

$\mathrm{Si}$, al final, en cualquier reconocimiento, puede vislumbrarse una normalización o domesticación que implicaría someter lo reconocido a lo ya conocido y admitido, frente a una forma de trato que se abriera a lo otro, a lo desconocido o a lo que en el otro se muestra como desconocido, habría una conexión con la mediación lingüística que tendría que admitir lo desconocido del otro, al modo de la hospitalidad respecto de la tolerancia. Del reconocimiento podría irse al respeto, de éste a la inclusión del otro, pero, finalmente, habría que ir hasta una hospitalidad más allá de la mera tolerancia, la que acoge al otro como plenamente distinto, es decir, no reconocido. En un contexto cosmopolita, la 
idea de una Europa que aceptara lo extranjero sin someterlo, sin normalizarlo, como ha defendido Derrida en El otro cabo, como se puede hacer desde otras posiciones filosóficas menos metonímicas o alegóricas, establecería políticamente tal conexión, permitiría que lo que no es cabo, apéndice, punta, pudiera aceptar lo que la vieja Europa puede ofrecer en la constelación postnacional, que lo que es extranjero no tomara lo europeo como algo siniestro, logocéntrico, eurocéntrico, etnocéntrico.

La inclusión del otro, de lo otro, de lo extraño, tiene como espacio relevante no el conocimiento como episteme, sino lo marginal, como ya vio Freud. En lo dejado al lado, brota la cuestión decisiva: lapsus, olvidos, sueños..., pero tambien en lo social como reproducción, en el periodismo que informa de lo que ya no aparece de modo inmediato para una comunidad, en el arte como sueño social o pesadilla, como apocalipsis. Y en la traducción como un asunto decisivo en lo cosmopolita. Inclusión de lo desconocido en el papel de la traducción, no mera reducción o reconocimiento de lo que se transmite por tal pretendido medio, tal es lo fundamental en tal torre de Babel moderna. Aseguraría una perspectiva contra el peligro de un purismo de la razón comunicativa o del reconocimiento, de los restos que todavía le quedan al acercarse más a lo determinado por la facticidad y la historia de los vencedores, en el sentido de Benjamin, que a lo indeterminado de lo que nos constituye y que pertenece a lo extranjero. Frente al reconocimiento a muchos niveles, aunque apunte a algo más que a la igualdad todavía no conseguida socialmente, se necesita incluir al otro, pero no para asimilarlo, sea por su normalización en una cultura determinada, sea por una traducción domesticante, sino en el desconocimiento, en la singularidad, en una apertura radical al otro que alcance ya el nivel de lo cosmopolita, es decir, de una confusión de lenguas ya sin original, sin lenguaje adámico.

En la traducción como mecanismo oculto en la globalización (Bielsa, 2009), donde flujos de información y de cosas y gentes se ven obligados a entenderse, por la profusión de lenguas y culturas, se abre la perspectiva de un más allá del reconocimiento que acepta lo desconocido, que se convierte en inclusión del otro. Es otro límite más avanzado, el que puede admitir nuestra capacidad de abrirnos a lo desconocido como algo en relación con los demás, en ellos mismos y en lo que les rodea. Como antes la racionalidad comunicativa ampliaba la noción cognitivo-instrumental de la razón, ahora se necesita ampliar la perspectiva del reconocimiento, hasta una traducción que deja pasar lo desconocido sin exigir contraseña.

Pero se necesita una noción de sujeto sensible a sus propias opacidades, a lo que lo mueve detrás de su consciencia e intenciones, consciente de lo desconocido en sí mismo para poder aceptar el desconocimiento en los otros y poderlos tomar como algo que sobrepasa al mero reconocimiento, desde el que se desvía con facilidad hacia el saber absoluto. Basta dar el paso hacia una comprensión de una subjetividad ligada al significante y al goce para hacer presente tanto las amenazas de lo intersubjetivo para cada sujeto como su necesidad de asumirlas, acogerlas, darles hospitalidad, pues en ellas somos y podemos ser más de lo 
que somos. Los límites de la misma racionalidad se harían presentes desde su interior, lo conmocionarían.

Algo no lejano de esta perspectiva es condición relevante para poder configurar una apertura cosmopolita al otro, que no deja de estar inspirada por una perspectiva europea y que aportaría a la constelación postnacional su voluntad democrática, igualitaria, de cuidado y respeto, de un conocer autorreflexivo que finalmente asume sus límites y, con ello, los amplía. Tal vez ello ayudaría a configurar mejor la idea de una democracia deliberativa (Benhabib) que superase las viejas democracias y su limitación a la idea de estado soberano o de nación, pues no sólo apuntaría a las formas de membresía, sino tambien a lo excluido y el modo de incluirlo, no meramente reconocerlo. En el concepto de humanidad kantiano, se ha abierto lo que ningún espíritu hegeliano permite pensar en una situación cosmopolita: la promesa de una política mundial que no excluyera a nadie, ni siquiera al desconocido que no puede ni reconocerse, que apenas puede luchar por el reconocimiento. Para darnos hospitalidad en un mundo postnacional donde todos ya somos extraños, pues ninguno está fuera de lo que debería ser su hogar.

\section{Referencias bibliográficas}

Adorno, Th. (1996). Introducción a la sociología. Barcelona: Gedisa.

Aguilera, A. (2002). "Atravesando la soberanía y el compromiso en arte». En: La Ortiga. Santander: Límite, 93-124.

BielsA, E. (2009). «Globalization, Political Violence and Translation: An Introduction». En: Bielsa, E. y Hughes, Ch. W. (2009). Globalization, Political Violence and Translation. Nueva York: Palgrave Macmillan.

Benhabib, Seyla (2006). El ser y el otro en la ética contemporánea. Barcelona: Gedisa.

Van den Brink, B. y Owen, D. (ed.) (2007). Recognition and Power. Nueva York: Cambridge University Press.

DerRidA, J. (1992). El otro cabo. Barcelona: Serbal.

Habermas, J. (1989). El discurso filosófico de la modernidad. Madrid: Taurus.

- (1987). Teoría de la acción comunicativa. Madrid: Taurus.

- (1999). La inclusión del otro. Barcelona: Paidós.

Honneth, Axel (2007). Reificación. Madrid: Katz.

- (2009a). Crítica del agravio moral. Buenos Aires: Fondo de Cultura Económica.

- (2009b). Patologías de la razón. Madrid: Katz.

- (2009c). Crítica del poder. Madrid: Mínimo Tránsito.

- (2011). Das recht der Freiheit. Berlín: Suhrkamp.

- (2007). Disrespect. Cambridge: Polity Press.

Honneth, A. y Fraser, N. (2006). ¿Redistribución o reconocimiento? Madrid: Morata. Menke, C. (1997). La soberanía del arte. Madrid: Visor. 